\title{
Rights and Professional Practice: How to Understand Their Interconnection
}

\author{
Asgeir Falch-Eriksen
}

\section{Introduction}

The UN Convention on the Rights of the Child (CRC) is a catalogue of rights specifically aimed at protecting the integrity of each individual child. ${ }^{1}$ By virtue of their humanity, children also carry other human rights, but the $\mathrm{CRC}$ is especially important to understand, given its sole purpose is to provide rights to children. The convention's potential lies within its global reach and its cosmopolitan human rights ethos. The human rights ethos is underpinned by the constitutional character of human rights, and the intention to safeguard and protect the rightsholder against different types of harm or to provide certain basic entitlements. A correct implementation and enforcement of the CRC would infuse the rights of the child in all areas of public regulation that affect children throughout childhood. Since so many nation-states claim to abide by the CRC, the CRC becomes increasingly important

\section{A. Falch-Eriksen $(\bowtie)$}

Norwegian Social Research, Oslo Metropolitan University, Oslo, Norway e-mail: asgeirer@oslomet.no 
to understand and especially with regard to professional practice and policy development.

With respect to human rights, the signatories to the convention have de facto, but not always de jure, committed themselves to implement and enforce the public protection of children as a matter of a child's individual right (see Sandberg 2018: Chap. 2 in this book):

Art. 19.1. States Parties shall take all appropriate legislative, administrative, social and educational measures to protect the child from all forms of physical or mental violence... while in the care of parent(s)...

Each signatory state must, in order to abide by the convention, operationalize the child's right to be protected as a positive entitlement. This can happen through budgets, through legal regulation, policy and professional decision-making on the street level (Goodin 1986; Lipsky 1980; Rothstein 1998).

When children become subjected to detrimental care, protection according to the CRC must not only abide by the formal-semantic intent of specific rights-provisions, but also positively enforce the CRC in accordance with the fundamental normative principle of human rights that underpins the convention itself. Such a fundamental human rights principle is conceptually prior to the specific rights-provisions of any human rights convention and can be referred to as a basic human rights standard. If we focus upon the CRC, we can argue in broad terms that such a standard constitutes a fundamental defence of the individual child's liberty and integrity against detrimental care or other illegitimate or unlawful treatment. ${ }^{2}$

The duty that each signatory state has taken on itself to enforce Art. 19.1 will in this chapter be referred to as the state's duty to implement and enforce rights-based child protection services. The convention's formal impact can hardly be understated. The rights of the child are to be infused and enforced 'in all matters concerning children' (ref. CRC Art. 3.1.). In order to accommodate the CRC throughout child protection services, that is its practices and through public policy, the CRC regulations and its human rights standard must actively become points of reference that set restrictions and demands and govern 'in all matters'. 
Accordingly, interpretation and active enforcement and implementation of the CRC through decision-making and through policy development must be constitutive to professional practice.

If a government is to make sure that child protection services become rights-based, it first needs to develop legal rules complying with human rights, and a system of protection that maintains the ethos of a human rights standard. Second, it needs to be vigilant in making sure that all extra-legal activities comply with the CRC and the basic principle of human rights. This is especially relevant with regard to public policy and professionalism. Since the CRC must be integrated and enforced in 'all actions concerning children', rights-based child protection must actively be made a part of all aspects of protection if the claim to abide by the CRC is to hold any merit. If for instance practical solutions make shortcuts, and argue that you do not need to have rigid decision-making designs that maintain the human rights standard because they are costly, or if the intervention is small, or we argue 'we know best', in such cases services de facto and de jure violate the human rights of the child, albeit in varying degrees.

This chapter will lay out theoretical propositions that combined will propose a way to understand the link between rights-based child protection and professional practice. The overarching goal is to build a bridge between the sociology of the professions, pertaining especially to different versions of social work for children, and a theory of rights. In sum, it will constitute building-blocks for a new theory of professionalism specifically aimed at rights-based child protection. It will not be possible to do justice to the complexity of such a theory on the whole in one chapter, and so the propositions will need to be further elaborated elsewhere.

A general rights-based approach to professional practice in child protection will need to draw eclectically upon four different strands of theory in order to become both conceptually coherent and have a high amount of explanatory power. The first is a theory of rights. It will be argued that the legitimacy and moral acceptability of protection according to rights depend on the level of constitutionality of the CRC within each nationstate, and how the material intent of the rights of the child is implemented procedurally in parallel with practices and policies of child protection that abide materially by rights themselves. 
The second is a theory of epistemology. It will serve as a backdrop to the type of knowledge that can and cannot feed into professional practice, provided it is supposed to be rights-based. Hence, the theory of epistemology is about limits to what can constitute knowledge. This does not mean a distinct epistemological theory for child protection, but that rights-based child protection defines certain challenges and restrictions on how to reach legitimate decisions based upon knowledge.

The third theoretical strand is drawn more directly from the sociology of the professions and is interlinked with a theory of epistemology. It revolves around professional practices being operative on street level and by a professional that is the final agent of implementation in the democratic chain of command.

The fourth strand is about rights-based childhood. It is a normative theory of what on the one hand constitutes childhood from the point of view of human rights, and on the other what the public system of government must do to make sure that children develop without being affected by any type of detriment to their individual integrity.

\section{A Theory of Rights and the Right to Protection}

Key to understanding the basic principle of human rights is the notion of individual liberty and the need for protecting individual liberty, that is the protection of freedoms of the individual against unlawful interference, barriers and domination as a matter of right (Alexy 2002; Locke 1823). Protections of these kinds rest on the individual negative right to liberty (Berlin 1958; Kant 1993). Adults can fully make use of their rights and act positively on them in all matters. Children, on the other hand, constitute a special case. Although they have the inherent right to all freedoms by virtue of their humanity, they are not always capable of adequately acting upon freedom, nor should they carry the burden of responsibility before they can be fit to make their own choices (Mill 1867; Rawls 1993).

We can thereby claim that although children have a negative right to individual liberty, children do not have the right to positively act upon 
freedoms (Mill 1867). Whenever needed, others must act on their behalf, either parents or others who are authorized in loco parentis (medical practitioners, teachers, child protection services etc.). Child protection as a right is a prohibition against causing harm through detrimental care of a child, that is care that constitutes ill-treatment. The child's right to protection is a matter of the public prohibiting every act of care that causes detriment to the child.

\subsection{Basic Human Rights Standard: Negative Right to Liberty}

Fundamental to a system of rights, of which the CRC is an operative expression, is the basic human rights standard. It can be more specifically referred to as the negative right to liberty. Isaiah Berlin explains what negative liberty entails:

I am normally said to be free to the degree to which no man or body of men interferes with my activity. Political liberty in this sense is simply the area within which a man can act unobstructed by others. If I am prevented by others from doing what I could otherwise do, I am to that degree unfree; and if this area is contracted by other men beyond a certain minimum, I can be described as being coerced, or, it may be, enslaved. (Berlin 1958)

From such a foundation, we can either extrapolate other negative rights, that is rights that differentiate the general negative right to liberty (e.g. freedom of speech, religion, family-life, privacy etc.), or we can develop other rights that cannot be in conflict with the individual negative right to liberty (e.g. positive rights: welfare rights, right to care, to education). Once conflict arises, the fundamental negative right to liberty must prevail if human rights are supposed to work according to the intention of protecting individual integrity through rights.

Hence, a system of rights has the negative right to liberty as a basic demand to rights-based systems at the point of departure, and such a basic right can be deemed as fundamental. The next category of rights is membership rights (usually referred to as citizenship), the third category 
is the right to legal remedies. These three categories, the way they are ordered, and how they are interdependent and interconnected, constitute a constitutional guarantee of individual freedoms and protection of integrity and, 'in a word, there is no legitimate law without these three' categories being enforced simultaneously (Habermas 1996). ${ }^{3}$

Without the first three categories of rights infused in law, and distributed equally to all, there could not be any personal freedom or personal equality before the law to speak of. These three categories of rights 'neutralize' the legal order, that is make it non-discriminatory, and infuse a thin conception of liberal morality to rule-of-law and practices derived from it. Such a thin concept of morality does not infringe upon reasonable doctrines that individuals can choose from regarding how they would live out their lives in a pluralistic society (Rawls 1993).

If individual liberty is to be secured, any individual must also be able to control and make use of their liberty to choose whatever reasonable way of life they desire. 'Neutralize' therefore alludes to the fact that individual liberty demands a legal order that is morally compatible with reasonable pluralism among everyone carrying citizenship, and which allows for any individual to choose their own rational plan of life as long as it abides by the Kantian precept of such a choice being compatible with everyone else having the same choice.

\subsection{The Child's Right to Liberty: The Special Case}

Children constitute a special case for a system of rights. Negative rights, membership rights and the right to legal remedies are not automatically applicable to children as such rights are applicable to adults, although children do carry the right to liberty (Alexy 2002; Mill 1867). Although some rights can be bestowed on youth who are still not autonomous adults (e.g. religious liberty, right to expression), children and youth cannot act fully positively on their negative rights until adulthood and when they are granted full citizenship independent from their care-takers. Full membership and the right to act upon a basic negative right to liberty require adulthood: 'to bring a child into existence without a fair prospect of being able, not only to provide food for its body, but instruction and 
training for its mind, is a moral crime' (Mill 1867). The lead reasons, from a system of rights perspective, is that a child is formally not able to reach competent and reasonable judgements, and have no rational plan of life (cf. the two moral powers in Rawls 1993).

Lacking the ability to act upon liberty, or autonomy, is the lead normative and political reason for excluding children from carrying rights as fully fledged citizens. Hence, a child, it can be argued, has a prospective right to individual liberty in the sense that the child only receives access to the complete system of rights once it reaches adulthood. Until then, the child depends on others to act according to the child's best interests, that is maintaining the integrity of the individual child. The child's right to protection against detrimental care is the right a child has for the state to prohibit parents from providing detrimental care, while such care goes against the child's best interests. Child protection services thereby raises a claim on acting in the child's best interests, against the claims of parents acting in the child's best interests, and consequently a claim that child protection services manage the child's negative right to liberty better than parents. We will now discuss what such a prospective right entails.

\subsection{The Prospective Right to Liberty}

The prospective right to individual liberty points both to the immediate and distant future of the particular child-when the child reaches adulthood and must be accountable for his or her own choices. After such a formal transition, the child becomes treated as autonomous, and as if it acts freely according to rational self-interest. Normally, a young adult cannot rely on others to reach decisions that are in the adult's best interests. As a child, on the other hand, others must reach decisions as to what is in the child's best interests. This means first of all that carrying a full set of rights, and being able to manage liberty, must be an essential part of what a child develops into. Second, and most importantly, others, parents or someone in loco parentis, must take care of the child's negative right to liberty on behalf of the child as long as the child has not reached adulthood. In this way, the principle of the child's best interests, which is operative in all actions concerning children (cf. CRC Art. 3.1), becomes 
a substitute principle for the basic negative right to liberty during childhood. In this way, the individual child's negative right to liberty is maintained.

If a child receives detrimental care, his or her ability to live life according to its own best interests becomes impaired by parents (or others). We can then argue that the child's integrity is violated. Once the parents expose the child to detrimental care, they do not act according to the child's best interests. As detrimental care is consequential for the integrity of the child, this type of care threatens the child's prospective right to liberty during childhood. This dimension of a rights-based child protection is pressed forward by the basic negative right to liberty, that is the human rights standard, immanent to a system of rights. By approximating what a human rights standard would entail to child-protection, the liberty principle becomes especially important as it must be a reference point for rights-based practice. As already argued, there would not be legitimate law if a basic negative right to liberty was not operative. Any practices in child protection that threaten the child's negative right to liberty would thereby be illegitimate. Now, if the right to liberty is to be carried by children who later becomes adults, we can argue that the state must intervene and make sure the child is cared for in those cases where the integrity of the child is threatened, all the way until the child reaches adulthood.

If, however, the care-takers provide detrimental care, and thereby risk damaging the child's integrity, the care also constitutes a violation of the child's prospective right to liberty as their integrity shifted into a development trajectory that was not good for the child. Eventually, the child's ability to act upon liberty, as adulthood kicks in, has become violated. The child's need for care throughout childhood is thereby intrinsically linked to the child's basic negative right to liberty once adulthood kicks in.

\subsection{Prospective Right to Liberty During Childhood}

When parents violate the child's negative right to liberty, the state must intervene not only to make sure this does not continue to happen, but 
more importantly safeguard that the development of the child is returned to a developmental track in accordance with the child's own trajectory; hence repairing the damage to the child's integrity caused by detrimental care, so that the child eventually can act upon a basic negative right to liberty.

Such a prospective right to liberty not only has consequences for how a childhood should be protected with regard to the future adult, but also how childhood is in need of protection according to the current needs of the child. The current needs of a child are continuously what feed into the development of the child. Hence, it is imperative that the quality of care during childhood is not to the specific child's detriment. ${ }^{4}$ If the child does not live a childhood free from detriment from moment to moment, the development will incrementally become stifled or skewed, and the individual child's ability to explore and develop as a person becomes impaired. The prospective right to liberty can thereby be a rights-based corrective for the role of child protection to push the child back on track so that development towards adulthood is what the child itself would want, that is according to the child's best interests.

\section{Limits to Epistemology: The Indeterminacy of a Child's Best Interests}

A bridge between rights and professional practice is based in an approach to epistemology, namely that knowledge and justified beliefs take a certain shape once the rights of the child are enforced. According to the $\mathrm{CRC}$ and the best-interests principle, professional practice must ensure that all actions that constitute child protection practice have the child's best interests as a primary consideration (Ref. CRC Art. 3.1.). What becomes challenging to the application of knowledge, and thus to the epistemology of rights-based professional child protection, is not only that every action, that is every decision, must have the child's best interests as a primary consideration, but also that a professional must know that such an aim is morally and factually indeterminate (Alston 1994; Elster 1987; Mnookin 1975; Mnookin 1985). 
What is implied by indeterminacy is that a decision in the child's best interests is always a value judgment-it is a matter of locating one triumphant rational best interest of any child above all other interests of that particular child. The two problems with the principle of the child's best interests are called the prediction problem and the evaluation problem (Mnookin 1975). The prediction problem alludes to the problem of making decisions without knowing what can be the spectrum of interests that a child has or will pursue in the near and distant future. The evaluation problem is about the uncertainty of the normative key to discern what is the best interest from the second best.

In order to illustrate the massive implication that rights have for professional practice, based on the notion that the best-interests principle is indeterminate, we can point to a widespread practice within organizational designs. In many nation-states decisions are reached by a single person throughout the organization. Even if we had access to all possible evidence, and an all-things-considered decision-making process made upon the same material, but by two equally competent and reasonable case-workers, different decisions would most likely be made. They can both be wrong and also equally correct. Knowing that nobody can say that they alone know what is in a child's best interest, a decision must become qualified, one way or the other, by reaching a decision that can be defended across a multitude of disciplinary platforms, different professions and civic opinions. ${ }^{5}$

Due to the fact of indeterminacy, the best interests of any child can only be assumed. Professional practice becomes a matter of simulating the child's own rational choice as if that child was an adult, and as if the child could make such a choice. Although no one knows exactly what is in a child's best interests, qualified claims can be raised. As such, a final decision can only reach rational acceptability through a procedure of claims that culminate in a final and ultimate claim acceptable to all as the rational thing to do (Alexy 1989; Falch-Eriksen 2012).

In order to qualify a decision, the process of approximating the best interests of the child through arguments must open up for all relevant types of arguments, and be based on all relevant types of knowledge, that is a multitude of knowledge bases in order to achieve an exhaustive and fully ventilated argumentative procedure that tests all types of potential 
best interests of the child. This includes, inter alia, psychology, law, medicine and social work. Although this might seem like a big demand, it is alluding to the very ethos of rights-based professional practice. It is thereby not only an ethical obligation, but also a matter of methodological attitude in practice-namely developing methods that are dynamic and open enough to fit every potential child (see Munro and Turnell 2018: Chap. 5 in this book).

A decision can only be reached when it can withstand criticism and carry an embedded mutual understanding across qualified opinions (Falch-Eriksen 2012). In order to activate all qualified opinions, decisionmaking procedures must be open, and decisions must follow a formal procedural logic embedded into a rule of approximation. The rule of approximation stipulates that all relevant claims assists in qualifying what is in the best interests of the child, but without making a claim upon a decision de facto being in the child's best interests. Once mutual understanding is reached across a multitude of different opinions and relevant arguments, a decision can claim to be the best one. The decision involves what Robert Alexy refers to raising 'the claim to correctness': 'The claim to correctness involved in the assertion of any legal statement is the claim that ... the assertion is rationally justifiable' (Alexy 1989). Only by infusing professional practice with some version of the approximation rule, so that decisions can be 'rationally justifiable', can a claim to correctness regarding what is in a child's best interests be raised.

\section{Theory of Professionalism}

A distinctive feature of modern nation-states is processes of professionalization and professionalism. Professionalism will in this regard be referred to as a combination of (1) the exercise of discretion when reaching decisions face to face with clients on street level, and (2) that the exercise of discretion is conducted according to some level of esoteric knowledge not easily nor conveniently accessible to a client, and (3) that practice choices are in accord with structural restrictions and the normative intent of the law (Abbott 2014; Goodin 1986; Lipsky 1980). Central to professionalization are both the increase of the use of discretionary decision-making 
based on knowledge, and also the advancement of knowledge development internal to a profession. In this sense, professionals also become the lead implementation and enforcement agents of the rights of the child.

\subsection{The Formal Restriction}

In the modern state-logic of delegating authority to professionals, the politicians also set restrictions and define the formal jurisdiction for the professions (Molander et al. 2012; Rothstein 1998). In this way, the knowledge base of the professions enters into a symbiotic relationship with the doctrine of nation-states and how they are governed through constitutional and democratic rule-of-law (Molander et al. 2012). Professionals are not only governed through regular law (where practices must be according to laws and policies), but they are also governed through settled and agreed-upon fundamental norms that are supposed to provide guidance as they distribute state resources according to their discretion. This is also where the human rights standard enters-as a fundamental guiding norm within the nation-state itself-which must pervade all relevant actions in the field of professional practice, also in the area where professionals are said to have discretion. The human rights standard, that is the basic negative right to liberty, is in its basic form constitutional, and provides guidance not only to politics, law-making and policy development, but also to professional practice on the street level.

Child protection systems have been delegated the authority to make decisions, that is perform professional discretion within a structure of laws, policies and rights. Provided that the parliament has decided that children's rights are to be enforced, the parliament will need to trust that every decision made by the child protection services enforces the principle of the child's best interests (Ref. CRC Art. 3.1). This also implies that professionals must be able to justify their actions according to the human rights standard, because the standard is a guiding norm, and thus a restrain on autonomy, on their decision-making (Molander et al. 2012).

If the professionals do not act in accordance with their delegated authority, which constitutes formal restrictions, and the discrepancy 
becomes too large between the democratic and constitutional ethos of the delegated authority and what the professional decides upon when acting upon discretion, the delegated authority must be revoked. Said differently, professionals that serve the role of gatekeepers within a nationstate must in all aspects of practice abide by laws, policies and fundamental norms to serve its purpose within the realm of rule-of-law. Hence, it is to be expected that professionals within child protection implement, enforce and maintain the rights of the child.

\subsection{Rule of Approximation Embedded in Professional Practice}

As we have already argued, there are many professional opinions as well as common-sense opinions about what constitutes non-detrimental care and the need for protection of children who are subjected to detrimental care. When arguments are offered about what action to proceed with, they are conditioned by the ability of professionals to solve practical problems. Furthermore, the human rights standard and the CRC set a distinct and real direction for what type of practice can be labelled as professional when applied to child protection.

Nobody has a monopoly upon what constitutes the best practice or best solution with regard to the best interests of the child. For instance, if a decision is reached only by a social worker, psychological knowledge will not be a substantial part of the deliberation, nor will law or medicine. If the decision were only conducted by laymen, then all scientific knowledge regarding children would be lost. It is no reason to either exclude any argument that might be deemed relevant, nor resort to only one set of arguments, although it might seem reasonable.

The rule of approximation implies that an optimal decision can only become established in an environment where all relevant arguments become sharpened through the resistance of open criticism. This does not mean that you always need a multitude of people sitting around a table, but that methods, practices, guidelines and so forth have the rule of approximation built into them. 
In the attempt to approximate a decision that is in a child's best interests, and which sets restrictions on what can be deemed as professional practice, we have now touched upon three challenges. First, nobody holds the right answer to the practical problem of what to do with the child and his or her care. Second, every argument that is relevant must be included. ${ }^{6}$ Third, a decision-making procedure must be able to extrapolate the relevant arguments in a fair manner. Due to these three challenges to each decision, the design of professional decision-making procedures approximating the child's best interests must on a fundamental level be formally rule-driven. To reach such an end, the approximation rule must abide by background principles underpinning general practical discourse, in which lies the potential of reaching decisions of mutual understanding.

Reaching a legitimate decision that rests upon mutual understanding can only be achieved if 'every rational being' becomes included to reach understanding (Kant 2002/1781). This precept is a limitation in the sense that in order to be regarded as a 'rational being' one must present relevant arguments, which implies being, at some level, affected or qualified by the goal of the decision. For instance: a parent is affected by the decision, whereby the medical practitioner affects the decision in a particularly qualified manner.Jürgen Habermas has formulated a discourse principle that incorporates the Kantian precept: 'valid for the will of every rational being'. It is a principle for the objective justification of norms in general:

'Only those norms are valid to which all affected persons could agree as participants in rational discourses' (Habermas 1996).

The discourse principle can thereby guide the rule of approximation as a design principle for an ideal standard of professional decision-making. By combining a rule of approximation to the discourse principle in decisionmaking designs, decision-making procedures will harbour the ability to reach mutual understanding through a rule-driven rational justification. Hence, mutual understanding ensures legitimate approximation of a child's best interests each time, that is a decision that upholds the child's prospective right to liberty. According to the discourse principle, legitimacy can only be reached through a discursive test that includes all those 
affected. Such a test can pragmatically be applied to decision-making designs in order qualify each decision. Hence, professionalism, with regard to ensuring the rights of the child in child protection, becomes a procedural concept in search of mutual understanding by approximating the best interests of the child.

By demanding that every relevant argument is to be raised and argued for before reaching a decision that holds the merits of rights-based professionalism, the discourse principle does not remove the need for determining the indeterminate of the best-interests principle, but it does strive for reaching a decision that can at least claim to be correct. This is what the ultimate goal must be since a valid or factually correct decision is impossible to reach. If the design of decision-making procedures attends the discourse principle during approximation, it could be assumed that an ultimate claim to correctness would arise at the intersections of arguments, where many different claims to correctness are raised and are potentially of equal strength.

\section{A Theory of Childhood in the Face of Professional Practice}

Any childhood is formative, significant and very complex, and the very right to protection is to protect against detrimental care during childhood. The purpose of this section is merely to present two circumstances of childhood that are important with regard to rights-based professional child protection. Any individual's right to personal liberty enables the carrier of such a right to freely choose how to live life as long as it does not restrain others from having the same opportunity. A consequence is that the social system where the individual resides will be in flux according to the aggregation of individual choices. Two main circumstances cause flux: reasonable pluralism (Rawls 1993), and the increasing complexity of modern societies (Giddens 1990). Flux influences how childhoods are conceived with regard to protection, what the different types are and what constitutes its nuts and bolts. Hence, flux challenges existing action norms of parents' reasonable choice of care, how children 
would want to live during childhood and how child protection services intervene.

The first circumstance is the magnitude of reasonable choices about how to live life, that is, the fact of reasonable pluralism (Rawls 1993). The gradual realization and implementation of the fact of reasonable pluralism have fragmented earlier common religious or sacred worldviews. It has in Weberian terms disenchanted the world and left it open for individuals to strive for whatever reasonable conception of good they want to choose (see Habermas 1996). By being confronted by an immense variety of childhoods and care-regimes, it becomes more apparent that servicedesign in child protection must embed a principle of equality of decisionmaking if professional practice is to emerge. Each type of childhood and each care-regime must be evaluated on its own merits, and whether or not care is sufficiently good must be decided upon in each case.

A child that receives detrimental care of the type that threatens their childhood and integrity needs protection on terms set by that child alone-that is according to the particular interests of the child. When a child's development is threatened to the extent that the child's integrity is in peril, those who intervene do it because it is a right of the child to have someone to take on the role of the parent and serve the best interests of the child.

Protection services must ensure that their care does not cause harm to the child's integrity and future ability to live a life he or she would want as an adult. If a type of care has caused harm to the child during childhood, the protection services must compensate or repair so that the child's integrity once again follows the track to which that particular child has a right.

\section{Concluding Remarks: The World Is the Limit}

In all relevant aspects of democratic rule-of-law, the respect of the integrity of each individual child must be coherent and visible. Modern state constructs that lay claim to abide by human rights must let a system of 
rights become constitutive of state-actions in the sense that you can trace the system of rights and explain how the state works by referring to a human rights standard. This is rarely the case. In most cases pragmatism kicks in, and we end up with practices that need to fit tight budgets, a varying degree of competence, varying decision-making designs and so forth. Ideal conditions are seldom present, but this is not an argument to stop reaching for it. Only by attempting to reach the ideal condition can we be certain to become better at the rights-based protection of children.

Nation-states' formal and informal commitment towards human rights can be treated as a counterfactual. This implies that, even if it is argued by nation-state politicians and public officials that child protection services of the nation-state uphold and maintain human rights (1) by taking such a position in public discourse, (2) by law-making assemblies making concessions within their legal orders towards such an end, (3) by developing practices within child protection towards such an end, (4) by providing organizational designs that harbour a rights-ethos, and (5) by bureaucratic decision-making that plainly refers to rights, all this does not mean that nation-states automatically respect human rights. Empirically, the dedication and conscious development towards human rights will obviously vary, and in many cases will even constitute practices in breach of human rights, although it is argued that nation-sates do in fact generally maintain human rights.

If we can argue that a nation-state is to de facto and de jure maintain and enforce the rights of the child, then we can critically discuss what such a dedication will imply for professional practice. This opens up a critical aim when discussing and assessing practices within child protection systems from the point of view of a basic human rights principle. For instance, if practices depart from human rights principles, then there is also something illegitimate with that practice, provided human rights are taken seriously. We can then go on to argue that if a nation-state claims to maintain and enforce the CRC, it cannot continue with practices that are in breach of the CRC's claim upon professionalism. Having such a focus, it is possible to critically assess and to unravel discrepancies between empirical practices that claim to maintain and enforce human rights on 
one hand and different theoretical propositions for practice that are founded upon a human rights principle on the other.

Every nation-state in for example Europe claims that they respect and uphold human rights while protecting children from detrimental care, and they do so often to legitimize politics and practices. If they claim to respect human rights, we can use such a claim as a counterfactual and move to the next step to discuss whether human rights are embedded in professional practices in child protection or not. Not forgetting that as long as the normative foundation of human rights is not an integrative force of social and political behaviour, it is to be expected that a society and a nation-state do not yet fully comply with human rights.

\section{Notes}

1. The concept of 'integrity' is complex and will not be discussed in this chapter. For this chapter it will suffice to argue that 'integrity' constitutes the quality of the person's character, especially infused by its interests, goals and well-being.

2. It will not be discussed here, but underpinning human rights is the defence of personal liberty from unlawful and illegitimate domination (see discussions from e.g. Berlin 1958; Dworkin 1977; Habermas 1996; Mill 1867; Rawls 1971).

3. There is also a fourth category referred to as political rights, and that secures the right to participation. The fifth category referred to is social welfare rights, or social rights. They are so-called positive rights and are usually implemented in order to safeguard a level of social justice and equality of opportunity. These categories of rights will not be problematized here.

4. The Universal Declaration of Human Rights is referenced in the CRC: 'children are entitled to special care and assistance'.

5. I will not discuss decision-making designs in this chapter. However, there are several ways to reach decisions that qualify arguments claiming to be in a child's best interests.

6. This holds true for any type of intervention, in-house interventions as well as out-of-home placements. However, the more severe the detriment, the more strict the demands towards decision-making must become. 


\section{References}

Abbott, A. (2014). The system of professions: An essay on the division of expert labor. Chicago: University of Chicago Press.

Alexy, R. (1989). A theory of legal argumentation: The theory of rational discourse as theory of legal justification. Oxford: Oxford University Press.

Alexy, R. (2002). A theory of constitutional rights. Oxford/New York: Oxford University Press.

Alston, P. (1994). The best interests principle: Towards a reconciliation of culture and human rights. In P. Alston (Ed.), The best interests of the child: Reconciling culture and human rights (pp. 1-25). Oxford: Clarendon Press.

Berlin, I. (1958). Two concepts of liberty: An inaugural lecture delivered before the University of Oxford on 31 October 1958. Oxford: Clarendon.

Dworkin, R. (1977). Taking rights seriously (new impression with a reply to critics. ed.). London: Duckworth.

Elster, J. (1987). Solomonic judgments-Against the best interest of the child. University of Chicago Law Review, 54(1), 1-45. https://doi. org/10.2307/1599714.

Falch-Eriksen, A. (2012). The promise of trust: An inquiry into the legal design of coercive decision-making in Norway. (2012 nr. 5), Høgskolen i Oslo og Akershus, Senter for profesjonsstudier, Oslo. Retrieved from http://hdl.handle.net/10642/1355

Giddens, A. (1990). The consequences of modernity. Cambridge: Polity Press.

Goodin, R. E. (1986). Welfare, rights and discretion. Oxford Journal of Legal Studies, 6(2), 232-261.

Habermas, J. (1996). Between facts and norms. Contributions to a discourse theory of law and democracy (W. Rehg, trans.). Cambridge, MA: The MIT Press.

Kant, I. (1993). Grounding for the metaphysics of morals: On a supposed right to lie because of philanthropic concerns. Indianapolis: Hackett.

Kant, I. (2002/1781). Critique of pure reason. Dent: Everyman.

Lipsky, M. (1980). Street-level bureaucracy: Dilemmas of the individual in public services. New York: Russell Sage Foundation.

Locke, J. (1823). Two treatises of government (Vol. 5). London: Thomas Tegg.

Mill, J. S. (1867). On liberty. London: Longmans, Green and Co.

Mnookin, R. H. (1975). Child-custody adjudication: Judicial functions in the face of indeterminacy. Law and Contemporary Problems, 39(3), 226-293. 
Mnookin, R. H. (1985). In the interest of children advocacy, law reform, and public policy. New York: W. H. Freeman \& Company.

Molander, A., Grimen, H., \& Eriksen, E. O. (2012). Professional discretion and accountability in the welfare state. Journal of Applied Philosophy, 29(3), 214-230. https://doi.org/10.1111/j.1468-5930.2012.00564.x.

Munro, E., \& Turnell, A. (2018). Re-designing organisations to facilitate rightsbased practice in child protection. In A. Falch-Eriksen \& E. Backe-Hansen (Eds.), Human rights in child protection. Implications for professional practice and policy. London: Palgrave Macmillan.

Rawls, J. (1971). A theory of justice. Cambridge, MA: The Belknap Press of Harvard University Press.

Rawls, J. (1993). Political liberalism. New York: Columbia University Press.

Rothstein, B. (1998). Just institutions matter: The moral and political logic of the universal welfare state. Cambridge: Cambridge University Press.

Sandberg, K. (2018). Children's right to protection under the CRC. In A. FalchEriksen \& E. Backe-Hansen (Eds.), Human rights in child protection. Implications for professional practice and policy. London: Palgrave Macmillan.

Open Access This chapter is licensed under the terms of the Creative Commons Attribution 4.0 International License (http://creativecommons.org/licenses/ by/4.0/), which permits use, sharing, adaptation, distribution and reproduction in any medium or format, as long as you give appropriate credit to the original author(s) and the source, provide a link to the Creative Commons license and indicate if changes were made.

The images or other third party material in this chapter are included in the chapter's Creative Commons license, unless indicated otherwise in a credit line to the material. If material is not included in the chapter's Creative Commons license and your intended use is not permitted by statutory regulation or exceeds the permitted use, you will need to obtain permission directly from the copyright holder.

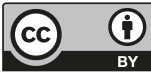

